\title{
Pay and conditions for NHS staff
}

\author{
Doctors may be included in new flexible arrangements
}

Among the many changes planned for the NHS are new pay policies for its staff, and their likely form has been set out in a review of the conditions of employment of staff employed in the NHS, which was undertaken for the Department of Health by Derek Warlow, a personnel director seconded from the South East Thames Regional Health Authority. ${ }^{1}$ It was based on interviews conducted in a balanced cross section of 32 discricts in five regions and represents the author's impression of what constituted majority opinions on the issues discussed. Questionnaires were not used and so no statistical summary is available with the report.

The main thrust of the report is to urge simplification of the rules governing conditions of employment for NHS staff and a shift in the balance of responsibility from statutory Whitley Council regulations and towards greater managerial discretion at local level. In arguing for this change the report is entirely consistent with recent more official documents from the Department of Health, such as the chief executive $\mathrm{Mr}$ Duncan Nichol's letter to general managers requiring them to establish district pay policies and to make effective use of the flexibility in both pay and grading made available in recent Whitley Council agreements. ${ }^{23}$

There are strong arguments to support this broad direction of change, including the widely heralded problems and shortages of staffing in the 1990s that will be caused by the rapid fall in the number of young people coming on to the job market. The effect will be variable; in London and the south east of England many skills are already in short supply, while in the north and north west some unemployment seems set to persist for years yet. These differences will make for wide variations in retention and recruitment prospects. As a result national changes in statutory pay rates and conditions are likely increasingly to be inadequate-not large enough to tackle the problems in the south east and too expensive of scarce resources by unnecessarily increasing NHS costs elsewhere.

The London weighting allowances are seen as too blunt an instrument and too geographically restricted to challenge the extent of labour shortage in the south east. Current thinking at the Department of Health is that the most effective help for hospitals facing difficulties with staffing is to give their managers more discretion to use flexibility both in grading and pay and in other terms and conditions of employment. This would allow districts more freedom of manoeuvre to sustain services - and hospital doctors will know that some of these freedoms are currently being used to ease supply problems with medical secretaries.

The Warlow report contains many recommendations for simplifying national regulations and extending local discretion. Greater flexibility is proposed in the application of agreements on hours of work to limit the use of the on call system, to avoid the voluntary nature of on call in some occupations, and to match hospital hours more to patients' preferences. Rules that limit overtime working and restrict labour mobility are recommended for local flexibility, and changes in annual leave are suggested together with the right to make sickness absence carry some penalties at local discretion. The report gives a clear impression that managers should have the right to introduce and use more incentives for performance within a proper framework of appraisal, and it proposes "district employment packages," which would allow managers the freedom to invest in accommodation, transport, removal, crèche facilities, meals, and mortgage support where they think these necessary to recruit scarce labour and compete effectively with non-NHS employers. Such packages would vary among districts according to their staff policies and employment difficulties.

The value - in principle - of greater local discretion will be widely supported at hospital level; at present even the continuity of clinical services is being put at risk by staff shortages. Already there are London hospitals where summer nursing shortages are causing long and widespread disruptions. If remedies are not found this position will worsen. The Warlow report does not, however, detail the expenditure controls necessary to avoid labour costs being pushed up by competition among neighbouring health districts. One way to give the plans greater financial realism would be a more overt recognition of the concept of "the pay fund," which was introduced with the administrative and clerical staffs' pay flexibility agreement last year. This first use of the pay fund limited the right of a district to increase the total cost of employing administrative and clerical staff to a maximum of $5 \%$ in the Thames regions and 3\% elsewhere. The fund concept requires the identification of all the resources used in pay, pensions, other conditions of work, recruitment costs, and so on, for each main group of staff (the pay fund); costs are then controlled by fixing the annual percentage change in the pay fund. Within this pay fund managers would be given wider discretion to balance the different elements in the "compensation package" in whatever way best delivered the 
clinical service. With decentralised budgets this management task would lie with budget holders who would be more likely to know the staff and to know what flexibility was viable and desirable. Such controls would make the policy more acceptable to the Treasury and would not undermine the freedom of manoeuvre wanted by managers.

I believe that the general thrust of the Warlow report deserves support, and it is important to state this to a medical audience-because the report is damaged by several recommendations on medical terms and conditions that are couched in simplistic terms and written in a somewhat offensive language. The report accuses consultants of resisting reductions in juniors' hours because it would mean an increase in consultants' own workload. Royal colleges are accused of having a negative influence on job descriptions that may lead to the closure of clinical services and unnecessarily high levels of medical staffing and also of playing an inappropriate part in limiting the performance of medical staff. Many of the issues Warlow raises are the old chestnuts such as the holding of contracts at district level, and most of them have already been discounted or rejected in the recent agreement on new job descriptions between the profession and the Department of Health.

What most doctors will see as crucial, however, is the implication for their pay - based for 30 years on recommendations from an independent review body - of the proposed greater flexibility and of pay funds. If present arrangements continue the separation of doctors' pay from other conditions of employment would effectively prevent them participating in the type of local packages envisaged; and yet such packages might help with recruitment problems to registrar posts in some specialties and with staff grade recruitment. The advent of NHS trusts and their freedom to determine medical pay and conditions will further destabilise present arrangements, and as the number of trusts increases the universality of Doctors and Dentists Review Body awards will diminish. One way to create more flexibility for doctors while retaining the neutral and independent role of the Doctors and Dentists Review Body might be to limit that role to determining the percentage size of the increment and to illustrating what this might mean for consultants still retaining traditional salary structures. Even such a limited change would be repugnant to many doctors who have seen national rates of pay as ensuring an even distribution of doctors throughout the country. The alternative, however, is the gradual erosion of the review body's influence as trusts shape new and more remunerative forms of medical contracts. When the National Health Service and Community Care Act 1990 finally gets its royal assent the profession will have to consider seriously the future role of the review body. This may not be as alarming as some traditionalists might think. The review body's supporters may well be embarrassed to find that these changes will begin to show the extent to which the review body has held down doctors' salaries in comparison with other senior NHS staff and non-NHS managers and professionals.

Director,

ROGER DYSON

Mercia Publications,

The Science Park, University of Keele,

Keele, Staffordshire ST5 5 SP

1 Warlow D. Review of the conditions of employment of staff employed in the National Health Service

(England, Wales and Scotland (1989)). London: Department of Health, 1989.
Nichol D. A \& C pay and grade restructure. London: Department of Health, 1989. (EL (89) MB/140.

3 Department of Health. Administrative and clerical staffs Whitley Council. London: Department of Health. 1989. Advance letter AC9/89.

\section{Traveller mothers and babies}

\section{Health authorities need to provide better care}

There are at least 12000 traveller gypsy caravans in Britain.' This community of over 60000 people belongs to one of Europe's oldest and most marginalised ethnic minorities. ${ }^{2}$ Like other groups on the edge of our society, including the homeless, ${ }^{3}$ they have difficulties gaining access to health care.$^{+5}$ Despite the introduction of specialist traveller health visitors in some health authorities ${ }^{6}$ many travellers still do not benefit from regular medical services, and many authorities have no policy on health care for this community.'

A recent report from the Maternity Alliance took a broad view of the maternal and perinatal health care provided for travellers. ${ }^{8}$ The fact that this group suffers poor health has already been well described. ${ }^{910}$ To its credit the Maternity Alliance did not go over that evidence again but instead looked at possible underlying factors. The report reminds us that the health of pregnant travellers and their babies depends partly on the facilities and environmental conditions of caravan sites: that is, the presence or absence of hot and cold running water, electricity, regular rubbish collection, and functioning toilets. Past studies have described the poor facilities found particularly on unofficial sites, ${ }^{911}$ and the Maternity Alliance claims, firstly, that many sites are still inadequate and, secondly, that the number of sites provided is insufficient for the traveller population. The report emphasises another factor that undermines maternal health and also jeopardises the provision of antenatal and perinatal care - the forcible eviction of traveller families from unofficial sites. "The best and most accessible antenatal care is of little avail if a mother is continually moved from one health district to another." ${ }^{\prime}$ Travellers need secure and safe stopping places.

The Maternity Alliance prompted the Association of Metropolitan Authorities to survey its members about provision for traveller families. The survey found that, of 43 responding authorities, almost a third would evict pregnant women "close to birth," and more than a third would evict pregnant women or mothers with a newborn baby. At least the metropolitan authorities replied; the Association of County Councils and the Association of District Councils "seemed unwilling to give any priority to investigating their members' policies with regard to Traveller mothers and babies." 8

The report moves beyond a critique of health and local authority policy (or apathy) towards travellers to positive recommendations. For local authorities these range from the development of "non-harassment" policies for pregnant or newly delivered mothers on temporary sites to the provision of basic environmental health amenities and regular liaison with health authorities and representatives of local travellers. The report calls on health authorities to include travellers' needs in the planning of services, to name a person to coordinate information relating to travellers, and to liaise regularly with local authorities, family practitioner com- 